LA GRANJA:

REVISTA DE

CIENCIAS DE LA VIDA

pISSN:1390-3799; eISSN:1390-8596

http:/ / doi.org/10.17163/lgr.n34.2021.02
Edición Especial/ Special Issue

Ciencias Geoespaciales

\title{
CARACTERIZACIÓN ESPECTRAL Y MONITOREO DE BOSQUES DE MANGLAR CON TELEDETECCIÓN EN EL LitORAL PACÍfico COLOMBIANO: BAJO BAUdó, CHOCÓ
}

\author{
SPECTRAL CHARACTERIZATION AND MONITORING OF MANGROVE FORESTS \\ WITH REMOTE SENSING IN THE COLOMBIAN PACIFIC COAST: BAJO BAUdÓ, \\ CHOCÓ
}

\section{Mauricio Alejandro Perea-Ardila*1 ${ }^{\mathbb{C}}$, Julian Leal-Villamil ${ }^{2}$ y Fernando Oviedo-Barrero $^{1}$ [i]}

${ }^{1}$ Centro de Investigaciones Oceanográficas e Hidrográficas del Pacífico-CCCP, Área de Manejo Integrado de Zona Costera, Capitanía de puerto de Tumaco, Tumaco, Colombia.

${ }^{2}$ Grupo Interdisciplinario de Investigación en Fruticultura Tropical. Universidad del Tolima, Barrio Santa Helena parte alta, Ibagué, Colombia.

*Autor para correspondencia: mapereaa@ut.edu.co

\section{Resumen}

El Pacífico colombiano posee extensas zonas en bosques de manglar (BM), que es un ecosistema estratégico de gran importancia ambiental y socioeconómica para la mitigación del cambio climático. Este trabajo tuvo por objetivo realizar la caracterización espectral y monitoreo de 66,59 km2 para cuatro densidades de BM en el Bajo Baudó (Colombia), empleando tres imágenes Landsat (1998, 2014 y 2017), combinaciones de bandas espectrales y tres índices de vegetación (IV) (Índice de Vegetación de Diferencia Normalizada-NDVI, Índice de Vegetación Ajustado al Suelo-SAVI y el Índice combinado de reconocimiento de manglares-CMRI). Los resultados demostraron que la mejor combinación de bandas espectrales para la identificación visual de los BM correspondió a infrarrojo color (NIR, Rojo, Verde) y falso color compuesto 1 (NIR, SWIR, Rojo). La firma espectral de los BM tuvo diferentes comportamientos para las cuatro densidades bajo las condiciones de pleamar y bajamar. Durante los 19 años analizados, se registró una diferencia de hasta el 17,9\% en el valor promedio de la reflectancia en los BM. De igual manera, los valores de IV fueron proporcionales a las densidades de BM, pero su valor se notó reducido por efectos de la marea al momento de la captura de las imágenes; los mayores aumentos de IV se registraron sobre la zona costera de transición tierra-agua donde existe una fuerte interacción con la condición mareal. Esta investigación aporta a la caracterización y monitoreo espacial de BM con sensores remotos y el estudio espectral de este importante ecosistema en Colombia.

Palabras clave: Marea, firma espectral, índices de vegetación, Landsat, reflectancia. 


\begin{abstract}
The Colombian Pacific has extensive areas in mangrove forests (MF), which is a strategic ecosystem of great environmental and socioeconomic for climate change mitigation. This work aimed to perform spectral characterization and monitoring of $66.59 \mathrm{~km} 2$ for four MF densities in Bajo Baudó (Colombia), using three Landsat images (1998, 2014 and 2017), combinations of spectral bands and three vegetation indices (VI) (Normalized Difference Vegetation Index-NDVI, Soil Adjusted Vegetation Index-SAVI and the Combined Mangrove Recognition Index-CMRI). The results showed that the best combination of spectral bands for visual identification of MF corresponded to infrared color (NIR, Red, Green) and false-color composite 1 (NIR, SWIR, Red). The spectral sign of MFs had different behaviors in four densities under the conditions of high tide and low tide. During the 19 years analyzed, there was a difference of up to $17.9 \%$ in the average reflectance value in MF. Similarly, the values of VI were proportional to the densities of MF, but their value was reduced by tidal effects at the time of capturing the images; the largest increases in VI were recorded over the coastal area of land-water transition, where there is a strong interaction with the tidal condition. This research contributes to the spatial characterization and monitoring of MF with remote sensors and the spectral study of this important ecosystem in Colombia.
\end{abstract}

Keywords: Tide, spectral signature, vegetation indexes, Landsat, reflectance.

Forma sugerida de citar: Perea-Ardila, M., Leal-Villamil, J. y Oviedo-Barrero, F. (2021). Caracterización espectral y monitoreo de bosques de manglar con Teledetección en el litoral Pacífico colombiano: Bajo Baudó, Chocó. La Granja: Revista de Ciencias de la Vida. Vol. 34(2):27-44. http: //doi.org/10.17163/lgr.n34.2021.02.

IDs Orcid:

Mauricio Alejandro Perea-Ardila: http:/ / orcid.org/0000-0003-4561-0251

Julian Leal-Villamil: http:/ / orcid.org/0000-0002-5100-2693

Fernando Oviedo-Barrero: http:/ / orcid.org/0000-0001-5559-1504 


\section{Introducción}

Los bosques de manglar (BM) son ecosistemas de alta importancia en zonas costeras de países tropicales y subtropicales, y poseen una alta relevancia en temas de conservación ya que albergan gran cantidad de especies de flora y fauna, además son fuente de sustento vital y económico de comunidades rurales (FAO, 2007; Monirul, Helena y Lalit, 2018). Los manglares son clave en el ciclo del carbono y en acciones para la mitigación del cambio climático (Kuenzer y col., 2011; Giri, 2016; Pham y col., 2019). A pesar de los múltiples beneficios, los $\mathrm{BM}$ a nivel mundial son fuertemente degradados, debido principalmente a actividades agrícolas, de expansión urbana, desarrollo costero y fenómenos inducidos como el aumento del nivel del mar (Rhyma y col., 2020). Por lo tanto, se hace necesario llevar a cabo un monitoreo regular en los BM, que contribuya al estudio del ecosistema y funcione como herramienta de planificación para la preservación de los servicios ecosistémicos para generaciones futuras (FAO, 2007).

Los BM se localizan en zonas intermareales de difícil acceso y con condiciones ambientales variables que limita en gran medida aspectos logísticos para llevar a cabo un monitoreo periódico en campo (Zhang y col., 2017; Jia y col., 2019). En este sentido, la Teledetección es una valiosa herramienta para llevar a cabo el monitoreo de estos ecosistemas, ya que permite monitorear los $\mathrm{BM}$ a escalas regionales y locales (Giri, 2016; Muhsoni y col., 2018). Los BM se identifican facilmente en las bandas infrarrojas debido a la cantidad de humedad en la vegetación (Purwanto y Asriningrum, 2019). Asimismo, estas características espectrales determinan la medición de la actividad fotosintética de los BM mediante el uso de índices de vegetación (IV) (Bannari y col., 1995; Rhyma y col., 2020).

El Índice de Vegetación de Diferencia Normalizada (NDVI, por sus siglas en inglés) propuesto por Rouse, Haas y Deering (1974) es uno de los más empleados para el estudio de la vegetación a nivel mundial (Chuvieco, 2010). Este IV tiene como característica principal la relación entre las bandas infrarroja y roja, lo cual determina eficientemente las diferencias en la absorción de luz de las plantas (Asner, 1998). El NDVI ha sido ampliamente utilizado para el monitoreo de los BM y presenta una fácil interpretación, ya que posee un rango de medición de -1 a +1 , donde los valores positivos reflejan zonas con presencia de vegetación (Rhyma y col., 2020).

Por otra parte, el Índice de Vegetación Ajustado al Suelo (SAVI, por sus siglas en inglés) (Huete, 1988) fue desarrollado para eliminar la influencia que tiene el suelo en la absorción de la reflectancia por la vegetación, este incluye el parámetro L el cual puede obtener valores entre 0 y 1 para eliminar el efecto del suelo, es decir, es un NDVI mejorado (Bannari y col., 1995). El Índice Combinado de Reconocimiento de Manglares (CMRI, por sus siglas en inglés) fue desarrollado por Gupta y col. (2018) para identificar exclusivamente BM, y tiene como característica principal la resta entre el NDVI y el Índice Diferencial de Agua Normalizado (NDWI, por sus siglas en inglés), facilitando el reconocimiento de los BM ya que incorpora el contenido de humedad de la vegetación. El CMRI posee un rango de medición entre -2 y +2 , donde los valores positivos representan zonas con presencia de BM. El uso de parámetros espectrales y el desarrollo específico de los IV ha permitido grandes avances en la obtención de información cuantitativa y cualitativa necesaria para la caracterización de BM en diferentes zonas (Conti, Sampaio y Cunha, 2016).

Diferentes estudios a nivel mundial han incorporado el uso de imágenes de sensores remotos y técnicas de teledetección para el monitoreo de manglares; tal es el caso de Rebelo-Mochel y Ponzoni (2007) quienes utilizaron imágenes Landsat 5 TM y datos de campo para caracterizar espectralmente cuatro especies en BM de la Bahía de Turiau al noreste de Brasil. Asimismo, Omar, Misman y Linggok (2018) emplearon imágenes Landsat para la caracterización de la firma espectral e implementaron el uso de IV para monitorear los cambios ocurridos en los BM de Malasia para tres fechas $(1990,2000$ y 2017). De igual manera, Ávila y col. (2020) determinaron la variación espacio-temporal de los BM en Cuba utilizando datos Landsat para un periodo de 35 años (1984 - 2019) e implementaron dos IV (NDVI y EVI) en su monitoreo para fines de conservación. Umroh y Sari (2016) utilizaron combinaciones de falso color en imágenes Landsat y el NDVI para monitorear las diferentes densidades de BM en la isla de Pongok en Indonesia. Por su parte, Rhyma y col. (2020) utilizaron el NDVI y diferentes valores 
de ajuste del parámetro L en el índice SAVI para el monitoreo de BM, usando imágenes de mediana resolución espacial en la reserva de Matang en Malasia. Por su parte, Chen (2020) implementó el uso del CMRI y el NDVI para el monitoreo de los BM en Dongzhaigang (China) con imágenes satelitales de mediana resolución.

A nivel regional, Galeano y col. (2017) usaron imágenes de sensores remotos de alta resolución incorporando el NDVI y factores climáticos en el monitoreo de $\mathrm{BM}$ en las islas del Rosario, en el Caribe colombiano. Asimismo, Perea-Ardila, OviedoBarrero y Leal-Villamil (2019) realizaron un mapeo de $\mathrm{BM}$ densos en el municipio de Buenaventura sobre la zona central del Pacífico colombiano y detallaron algunas características espectrales básicas de este ecosistema usando imágenes Sentinel 2. Los estudios mencionados anteriormente resaltan la importancia del uso de la teledetección para la caracterización del monitoreo de $\mathrm{BM}$ a diferentes escalas y con diferentes enfoques metodológicos.

Colombia, a lo largo del litoral Pacífico, posee aproximadamente 2094,03 $\mathrm{km}^{2}$ de manglares (Rodríguez-Rodríguez y col., 2016) extensión que puede corresponder entre el 70 y $80 \%$ del total de BM del país (Wilkie y Fortuna, 2003). Este ecosistema requiere de monitoreo constante, ya que en términos de conservación brinda múltiples servicios ecosistémicos y es considerado como un ecosiste- ma altamente amenazado por el cambio climático (Chow, 2017). El presente trabajo tiene como objetivo el uso de técnicas de teledetección y la aplicación de tres índices de vegetación (NDVI, SAVI, CMRI) para caracterizar espectralmente y monitorear cuatro densidades de BM, utilizando imágenes Landsat de tres años (1998, 2014 y 2017) en diferentes estados mareales en el Bajo Baudó-Chocoano. Con los resultados obtenidos en esta investigación se avanzará en el estudio espectral y monitoreo espacial de $\mathrm{BM}$ con imágenes Landsat en ecosistemas costeros estratégicos de Colombia.

\section{Materiales y Métodos}

\section{1 Área de estudio}

La zona de estudio se localizó al norte del Pacífico colombiano, sobre la zona costera del municipio de Bajo Baudó, departamento del Chocó (Figura 1). El área de acuerdo con la clasificación de zonas de vida establecida por Holdridge (1978) corresponde a un Bosque Muy Húmedo Tropical (bmhT). La precipitación anual oscila entre los 4000 y $7000 \mathrm{~mm}$ de lluvia y presenta una temperatura promedio anual superior a $24^{\circ} \mathrm{C}$ (Blanco, Escobar-Sierra y CarvajalQuintero, 2014). Las geoformas del terreno y las condiciones climáticas del área propician que los $\mathrm{BM}$ se encuentren mayormente de forma continua sobre la costa y presenten alturas superiores a los 40 m (Rodríguez-Rodríguez y col., 2016).

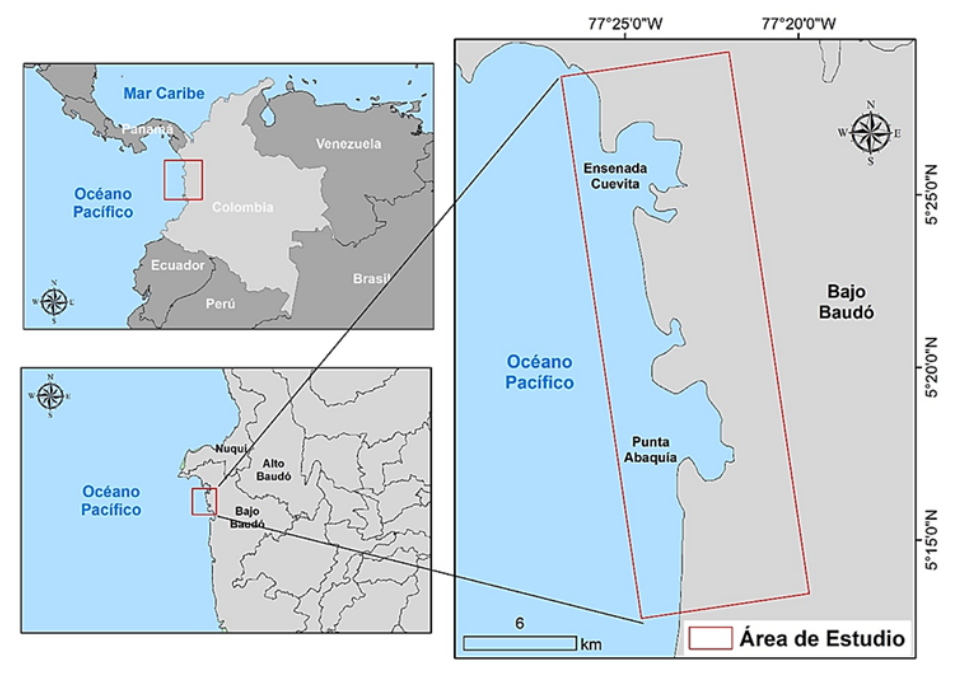

Figura 1. Localización del área de estudio. 
El flujograma utilizado en esta investigación se presenta en la Figura 2, y dentro de los procesos utilizados se contempló (i) el procesamiento digital de imágenes Landsat, (ii) el análisis espectral de bosques de manglar por medio de la firma espectral y (iii) el cálculo de índices de vegetación para las diferentes densidades de manglares. De igual manera, el manejo de datos geoespaciales y análisis de las imágenes Landsat se realizó con el software ArcGIS 10,3 (ESRI 2014).

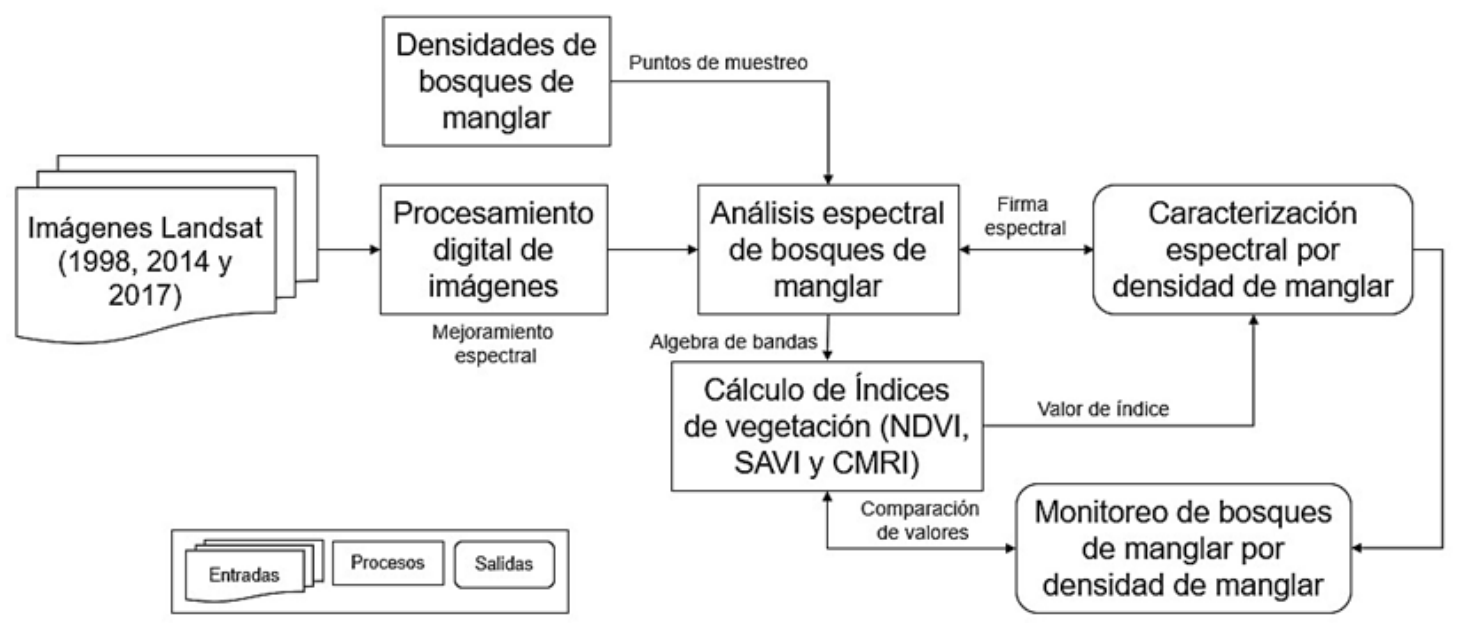

Figura 2. Flujograma utilizado.

\subsection{Imágenes de sensores remotos}

Se utilizaron tres imágenes Landsat con resolución espacial de $30 \mathrm{~m}$ correspondientes a los años 1998, 2014 y 2017 (USGS, 1998; USGS, 2014; USGS, 2017), estas imágenes fueron descargadas libremente a través del portal oficial del Servicio Geológico De Estados Unidos (USGS, por sus siglas en inglés) https://earthexplorer.usgs.gov/ (USGS, 2020). La selección de las imágenes correspondió a productos que no presentaron afectación por nubes, ya que esta zona permanece con una alta nubosidad durante la mayor parte del año (Tabla 1).

La información de las condiciones mareales se identificó con base a los datos de la RedMPOMM (Red de Monitoreo de Parámetros Oceanográficos y de Meteorología Marina) de Colombia, de la Dirección General Marítima (https://geohub-dimar. opendata.arcgis.com/) (Dirección General Marítima., 2020). En este paso se identificó la fecha y hora de captura de la imagen Landsat y se validó con respecto a las condiciones de la marea registradas para ese momento.

\subsection{Preprocesamiento de imágenes satelita- les}

Las imágenes se sometieron a un preprocesamiento, y se transformaron sus Niveles Digitales (ND) a unidades físicas (reflectancia al tope de la atmosfera-ToA) empleando los parámetros para la normalización de la reflectancia establecidos por Ariza (2013) y USGS (2018b) para las imágenes Landsat 8 y los de Chander y Markham (2003) y USGS (2018a) para las imágenes Landsat 5 y 7, respectivamente (Tabla 2). De igual forma, se realizó el recorte de las imágenes conforme el área de estudio, y posteriormente se efectuó la fusión de bandas para su respectivo análisis.

\subsection{Definición de las densidades de bosques de manglar}

Se utilizó información vectorizada del año 2019 correspondiente a la densidad de BM del a escala 1:2000 elaborada por el Centro de investigaciones Oceanográficas e Hidrográficas del Pacífico-CCCP (DIMAR-CCCP, 2013). Esta cartografía se realizó bajo técnicas de interpretación visual de imágenes 
utilizando ortofotos de muy alta resolución espacial y datos de Light Detection and Ranging (LIDAR, por sus siglas en inglés) que posee la caracterización espacial de los diferentes BM frente a su densidad y altura, lo que permitió establecer cuatro categorías de densidad que correspondieron a: Manglares
Denso Alto (MDA), Manglar Abierto Alto (MAA), Manglar Denso Bajo (MDB) y Manglar Abierto Bajo (MAB). Con esta capa se realizó una máscara donde se definieron los límites de la cobertura de manglar en las imágenes Landsat y se determinaron sus correspondientes densidades.

Tabla 1. Características de las imágenes Landsat empleadas.

\begin{tabular}{lccc}
\hline Característica & Landsat 5 TM & Landsat 8 OLI & Landsat 7 ETM+ \\
\hline ID Producto & LT50100561998003CPE00 & LC80100562014239LGN01 & LE70100562017111EDC00 \\
Fecha de captura & $03 / 01 / 98$ & $27 / 08 / 14$ & $21 / 05 / 17$ \\
Columna/Fila & & $010-056$ & $21,00 \%$ \\
Cobertura de nubes & $16,00 \%$ & $18,53 \%$ & $64,39^{\circ}$ \\
Ángulo solar & $46,62^{\circ}$ & $63,51^{\circ}$ & 8 Bits \\
Resolución radiométrica & 8 Bits & 12 Bits & Banda 1 - Azul (0,45-0,52) \\
& Banda 1 - Azul (0,45-0,52) & Banda 2 - Azul (0,45-0,51) & Banda 2 - Verde (0,52-0,60) \\
Longitud de onda & Banda 2 - Verde (0,52-0,60) & Banda 3 - Verde $(0,53-0,59)$ & Banda 3 - Roja (0,63-0,69) \\
& Banda 3 - Roja (0,63-0,69) & Banda 4 - Roja (0,64-0,67) & Banda 4 - NIR (0,77-0,90) \\
Estado de marea & Banda 4 - NIR (0,77-0,90) & Banda 5 - NIR (0,85-0,88) & Bajamar \\
Proyección & Banda 5 - SWIR1 (1,55-1.75) & Banda 6 - SWIR1 (1,57-1.65) & Banda 5 - SWIR1 (1,55-1.75) \\
\hline
\end{tabular}

Basada en el metadato de las imágenes y registros de marea de la RedMPOMM.

\subsection{Análisis espectral de bosques de man- glar}

Para observar el comportamiento de los BM en las diferentes longitudes de onda, se utilizaron 4 combinaciones de bandas descritas por Horning (2014) y Franco (2017), las cuales fueron: color verdadero (Rojo, Verde, Azul), infrarrojo color (NIR, Rojo, Verde) y falso color compuesto 1 (NIR, SWIR, Rojo) y falso color compuesto 2 (SWIR, NIR, Rojo). Para cada imagen se digitalizaron polígonos para el enmascaramiento de las nubes con el fin de evitar la influencia de las nubes y sombras en análisis espectral de los BM (Zhu y Woodcock, 2014; Pimple y col., 2018). De acuerdo con las recomendaciones de muestreo estadístico para análisis espectrales brindadas por Congalton (1991), se estableció al azar 200 puntos de muestreo distribuidos equitativamente entre las diferentes densidades de BM (50 para cada densidad establecida), se establecieron los valores de reflectancia ToA promedio para cada imagen y se registraron las firmas espectrales correspondientes en el periodo de tiempo evaluado.

\subsection{Cálculo de Índices de vegetación}

Para efectuar el monitoreo de los BM en el periodo de tiempo seleccionado, se utilizaron los tres IV descritos en la Tabla 3.

\subsection{Monitoreo de bosques de manglar con índices de vegetación}

Se realizó una comparación entre los valores de IV, teniendo en cuenta como referencia las densidades de BM para 1998-2014, 2014-2017 y 1998-2017 y se identificó la variación del valor de IV para cada densidad; se efectuaron las comparaciones gráficas entre el valor IV y la densidad del BM, donde se determinó el comportamiento para cada periodo de tiempo estudiado. 
Tabla 2. Parámetros para la calibración de las imágenes Landsat.

\begin{tabular}{ll}
\hline Sensor & Ecuación \\
\hline & $L_{\lambda}=\left(\frac{L M A X_{\lambda}-L M I N_{\lambda}}{Q c a l m a x-Q c a l m i n}\right)\left(Q_{c a l}-Q_{\text {calmin }}\right)+L M I N_{\lambda}$ \\
& $\rho_{\lambda}=\frac{\pi L_{\lambda} d^{2}}{E S U N_{\lambda} \cos \theta_{s}}$ \\
& Dónde: \\
& $L_{\lambda}:$ Radiación espectral en la apertura del sensor $\left[W /\left(m^{2} s r \mu m\right)\right]$. \\
Landsat 5 TM & $Q c a l:$ Valor de píxel calibrado cuantificado $[D N]$. \\
& $Q c a l m i n:$ Valor mínimo cuantificado del píxel calibrado $[D N]$. \\
& $Q c a l m a x:$ Valor máximo cuantificado del píxel calibrado $[D N]$. \\
& $L M I N_{\lambda}:$ Radiancia espectral en el sensor que se escala a Qcalmin $\left[W /\left(m^{2} s r \mu m\right)\right]$. \\
& $L M A X_{\lambda}:$ Radiancia espectral en el sensor que se escala a Qcalmax $\left[W /\left(m^{2} s r \mu m\right)\right]$. \\
& $\rho_{\lambda}:$ Reflectancia planetaria del ToA. \\
& $d:$ Distancia Tierra-Sol [unidades astronómicas $].$ \\
& $E S U N_{\lambda}:$ Irradiancia solar media exoatmosférica $\left[W /\left(m^{2}\right)\right]$. \\
& $\theta_{s}:$ Ángulo cenital solar. \\
& $\rho_{\lambda}^{\prime}=\frac{M_{p} Q_{c a l}+A_{p}}{\text { sen } \theta_{s e}}$ \\
& \\
& Dónde: \\
& $\rho_{\lambda}^{\prime}:$ Reflectancia planetaria en el techo de la atmosfera ToA. \\
& $M_{p}:$ factor multiplicativo de escalado especifico. \\
& $Q_{c a l}:$ Valor de píxel calibrado cuantificado. \\
& $A_{p}:$ Factor aditivo de escalado especifico. \\
& $\theta_{s e}:$ Ángulo de elevación solar del centro de la escena. \\
\hline &
\end{tabular}

Tabla 3. Descripción de los índices de vegetación e índice de agua empleados en este estudio.

\begin{tabular}{lll}
\hline \multicolumn{1}{c}{ Índice } & \multicolumn{1}{c}{ Ecuación } & \multicolumn{1}{c}{ Referencia } \\
\hline Índice de Vegetación de Diferencia Normalizada (NDVI) & $\frac{N I R-\text { Red }}{N I R+\text { Red }}$ & Rouse, Haas y Deering (1974) \\
Índice de Vegetación Ajustado al Suelo (SAVI) & $\frac{N I R-R e d}{N I R+R e d+L}(1+L)$ & Huete (1988) \\
Índice de Agua deDiferencia Normalizada (NDWI)* & $\begin{array}{l}\text { Green }-N I R \\
\text { Índice Combinado deReconocimiento de Manglares (CMRI) }\end{array}$ & GDVI-NDWI (1996) \\
\hline
\end{tabular}

Donde: $\mathrm{L}=0,5$. *El NDWI solo se utilizó para determinar el CMRI.

\section{Resultados}

\subsection{Preprocesamiento de imágenes satelita- les}

Los ND de las imágenes se transformaron a valores de reflectancia ToA (Tabla 4), lo que permitió obtener una mejora radiométrica eliminando en gran medida los efectos atmosféricos presentes en los productos originales. Asimismo, se efectuó el recorte de las imágenes al área de estudio y se enmascararon las nubes presentes en el área de estudio.

\subsection{Densidad de bosques de manglar}

De acuerdo con la información digital descrita en DIMAR-CCCP (2013), se realizó el análisis de la distribución espacial y densidad de los $\mathrm{BM}$ en el área de estudio, y se encontró una extensión total de BM de $66,59 \mathrm{Km}^{2}$, siendo la densidad de Manglar Denso Alto (MDA) la más predominante en la zona, mientras que el Manglar Abierto Bajo presentó la menor extensión en el sitio de estudio (Tabla 5). 
Tabla 4. Resumen estadístico de los valores de reflectancia obtenidos a partir de las imágenes Landsat.

\begin{tabular}{|c|c|c|c|c|c|c|c|c|c|c|c|c|c|c|c|}
\hline \multirow{3}{*}{ Parámetros } & \multicolumn{15}{|c|}{ Imagen Landsat empleada } \\
\hline & \multicolumn{5}{|c|}{ Landsat TM (1998) } & \multicolumn{5}{|c|}{ Landsat OLI (2014) } & \multicolumn{5}{|c|}{ Landsat ETM+ (2017) } \\
\hline & B1 & $\mathrm{B} 2$ & B3 & B4 & B5 & $\mathrm{B} 2$ & B3 & $\mathrm{B} 4$ & B5 & B6 & B1 & $\mathrm{B} 2$ & B3 & B4 & B5 \\
\hline Min & 0,00 & 0,00 & 0,00 & 0,01 & 0,00 & 0,07 & 0,04 & 0,02 & 0,00 & 0,00 & 0,01 & 0,01 & 0,01 & 0,03 & 0,00 \\
\hline Max & 0,44 & 0,89 & 0,76 & 0,95 & 0,63 & 0,75 & 0,75 & 0,79 & 0,90 & 0,59 & 0,34 & 0,38 & 0,35 & 0,80 & 0,50 \\
\hline Prom & 0,03 & 0,05 & 0,03 & 0,17 & 0,07 & 0,10 & 0,08 & 0,06 & 0,20 & 0,09 & 0,03 & 0,04 & 0,03 & 0,32 & 0,13 \\
\hline Std & 0,03 & 0,05 & 0,03 & 0,14 & 0,05 & 0,04 & 0,04 & 0,05 & 0,15 & 0,06 & 0,03 & 0,03 & 0,03 & 0,19 & 0,07 \\
\hline
\end{tabular}

Tabla 5. Densidad de bosques de manglares presentes en el área de estudio.

\begin{tabular}{|c|c|c|c|c|}
\hline $\begin{array}{c}\text { Densidad de } \\
\text { manglar }\end{array}$ & Descripción & $\begin{array}{c}\text { Área } \\
(\mathrm{Km} 2)\end{array}$ & $\begin{array}{c}\text { Extensión } \\
(\%)\end{array}$ & Detalle \\
\hline $\begin{array}{l}\text { Manglar } \\
\text { Denso Alto } \\
\text { (MDA) }\end{array}$ & $\begin{array}{l}\text { Manglares con alturas superiores a los } \\
15 \text { m cuya densidad representa más } \\
\text { del } 70 \% \text { de cobertura en su unidad. }\end{array}$ & 53,60 & 80,49 & \\
\hline $\begin{array}{l}\text { Manglar } \\
\text { Abierto Alto } \\
\text { (MAA) }\end{array}$ & $\begin{array}{l}\text { Manglares con alturas superiores a los } \\
15 \text { m cuya densidad representa entre } \\
\text { el } 30 \text { y } 70 \% \text { de cobertura en su unidad. }\end{array}$ & 9,28 & 13,94 & \\
\hline $\begin{array}{l}\text { Manglar } \\
\text { Denso Bajo } \\
\text { (MDB) }\end{array}$ & $\begin{array}{l}\text { Manglares con alturas inferiores a los } \\
15 \text { m cuya densidad representa más } \\
\text { del } 70 \% \text { de cobertura en su unidad. }\end{array}$ & 3,18 & 4,78 & \\
\hline $\begin{array}{l}\text { Manglar } \\
\text { Abierto Bajo } \\
\text { (MAB) }\end{array}$ & $\begin{array}{l}\text { Manglar con alturas inferiores a los } \\
15 \text { m cuya densidad representa entre } \\
\text { el } 30 \text { y } 70 \% \text { de cobertura en su unidad. }\end{array}$ & 0,53 & 0,8 & \\
\hline TOTAL & & 66,59 & $100.00 \%$ & \\
\hline
\end{tabular}

\subsection{Análisis espectral de bosques de man- glar}

Se obtuvieron 4 combinaciones espectrales para los productos satelitales, y se pudo diferenciar visualmente los BM frente a otras coberturas vegetales (Tabla 6). La combinación verdadero color evidenció que la vegetación de BM presentó tonos verdes oscuros y un brillo bajo para la imagen de 1998 y
2014 y ligeramente un tono verde más claro para la imagen del 2014 que no es influenciada por la marea. Para la combinación infrarrojo color, el BM presentó tonos de rojo oscuro y con bajo brillo, la imagen del 2014 en pleamar presentó un brillo mucho más bajo, resaltando los grandes contenidos de humedad de la vegetación frente a las otras coberturas vegetales que presentaron tonos rojizos a rosados. De igual manera, para la combinación falso 
color compuesto 1, el BM presentó un color marrón con un tono oscuro para la imagen de 1998 y 2014, demostrando grandes contenidos de humedad en la vegetación y presentando gran contraste frente a las demás coberturas. La combinación falso color compuesto 2 reveló una coloración verde moderadamente oscura, permitiendo el fácil reconocimiento de la cobertura; sin embargo, se observaron diferencias en las tonalidades respecto al estado mareal.

Tabla 6. Combinaciones de bandas empleadas en el estudio.

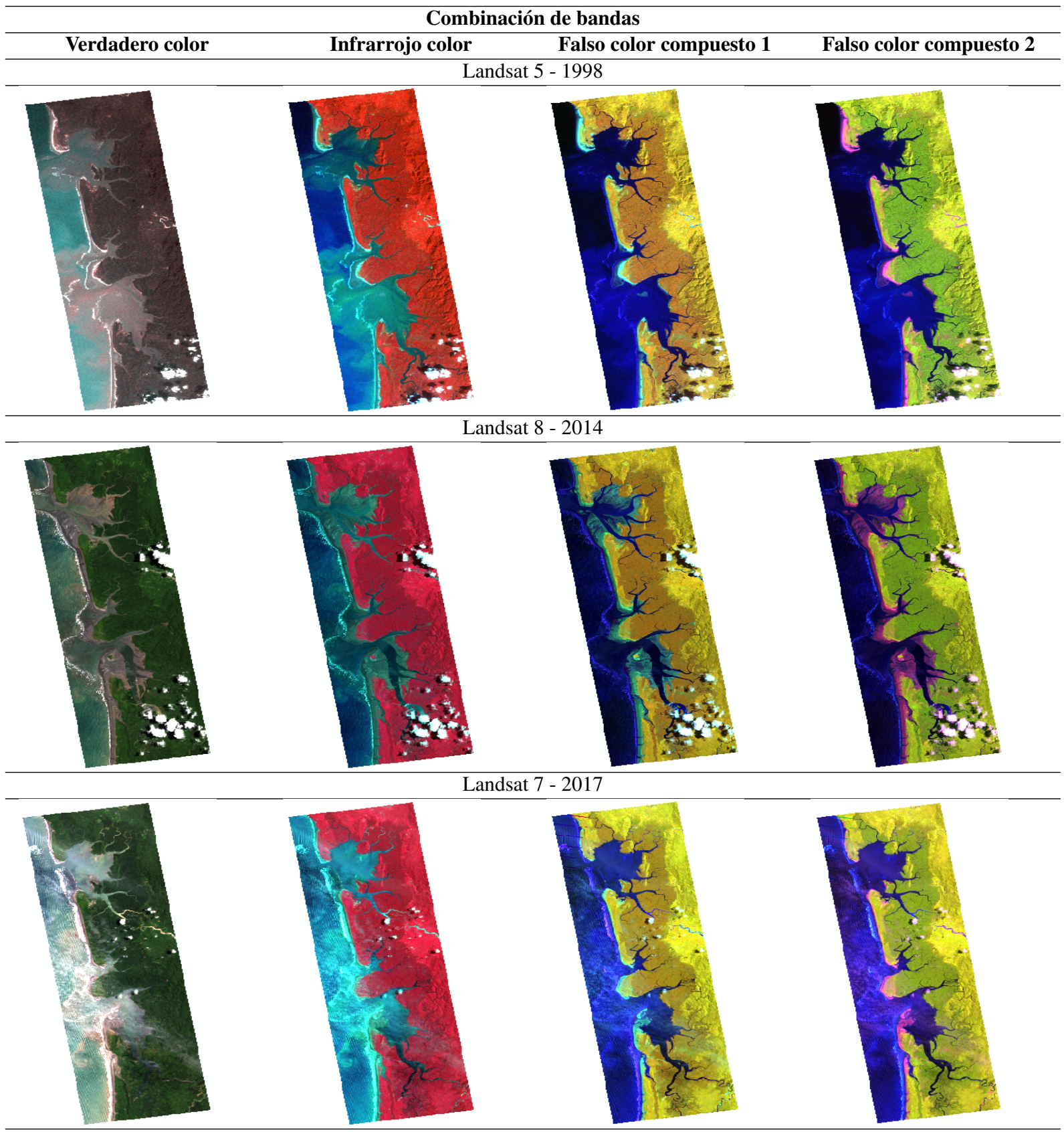




\subsection{Firma espectral de bosques de manglar}

La firma espectral para la reflectancia ToA se calculó para las tres imágenes (Figura 3). Se encontró

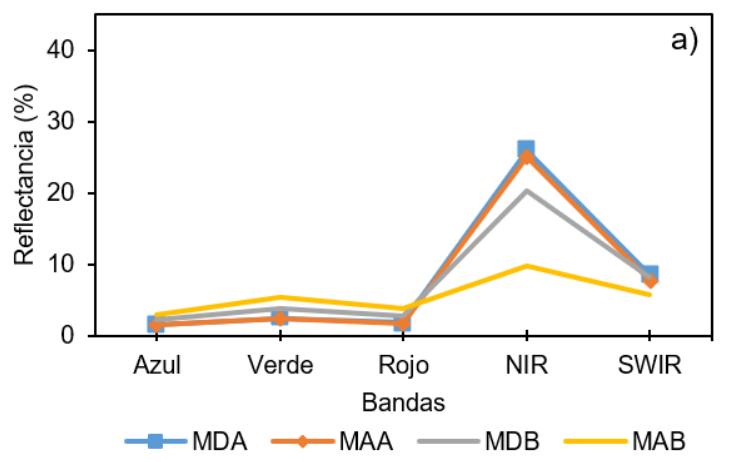

que la reflectancia promedio para la banda NIR de la imagen de 2017 con respecto a la reflectancia NIR de 2014 y 1998 mostró una diferencia de 12,6\% y $17,9 \%$, respectivamente.
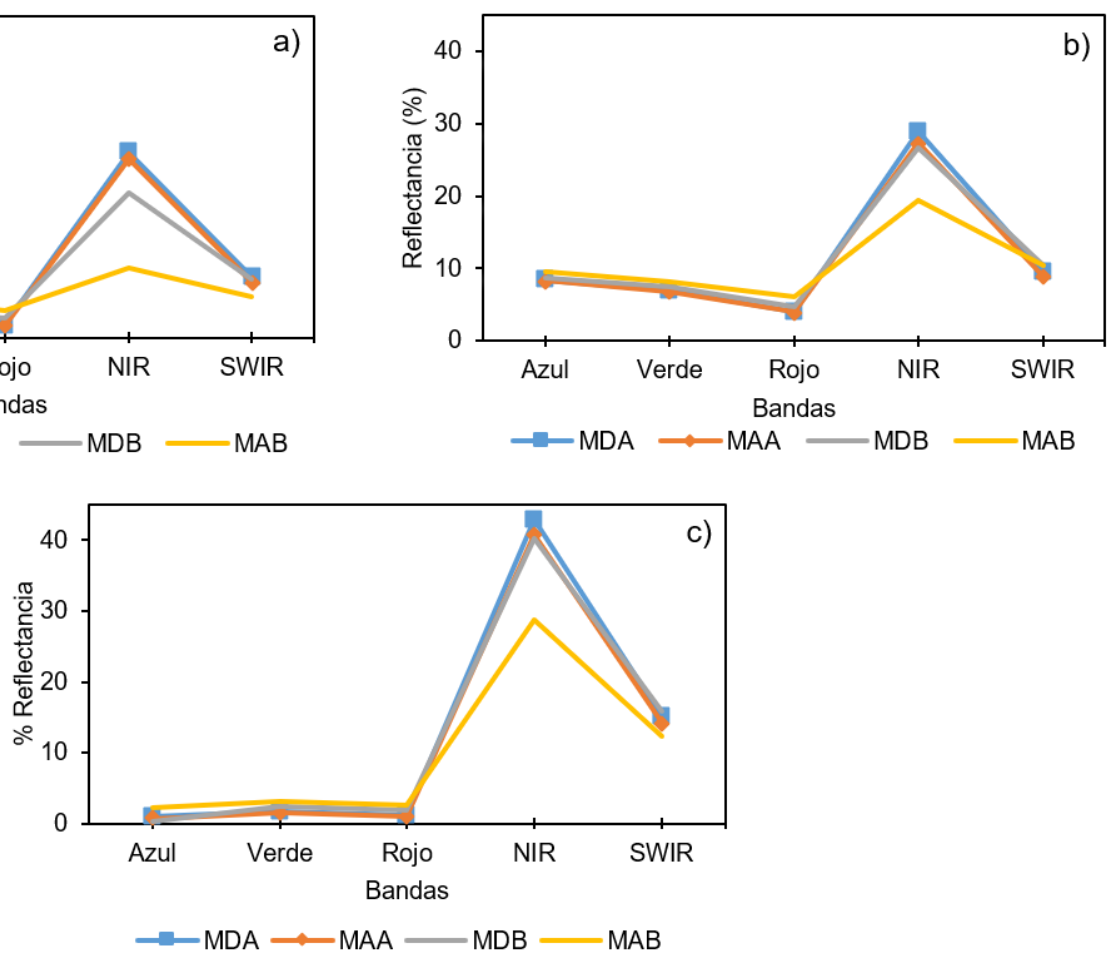

Figura 3. Firma espectral estimada para los BM en los productos Landsat a) 1998, b) 2014 y c) 2017. Dónde: Manglar denso alto (MDA), Manglar abierto alto (MAA), Manglar denso bajo (MDB), Manglar abierto bajo (MAB).

En todos los casos presentados, los $\mathrm{BM}$ en sus diferentes densidades (MDA, MAA, MDB y MAB) presentaron valores de reflectancia más elevados en el infrarrojo cercano, siendo coherente con la firma

\section{5 Índices de vegetación}

Se observó que los valores para la densidad de MAB en los tres IV en el año de 1998 fueron los más bajos con 0,28, 021 y 0,41 para el NDVI, SAVI y CMRI, respectivamente (Figura 4). Se encontró que los valores de IV tienden a disminuir ligeramente según la espectral promedio de la vegetación. En tal sentido, los valores de reflectancia mínimos, máximos y promedios registrados para cada densidad de BM se presentan en la Tabla 7.

densidad y también se percibió que las condiciones de pleamar en la imagen de 2014 tienden a registrar valores más bajos de IV con respecto a la imagen de 2017. En la Tabla 8 se presentan los valores mínimos, máximos y promedios de los IV registrados para cada año en las diferentes densidades de BM presentes en el área de estudio. 
Tabla 7. Valores promedio de reflectancia estimados para las densidades de bosques de manglar.

\begin{tabular}{|c|c|c|c|c|c|c|c|c|c|c|c|c|}
\hline \multirow[t]{3}{*}{ Banda } & \multicolumn{12}{|c|}{ Landsat $5-1998$} \\
\hline & \multirow{2}{*}{\multicolumn{3}{|c|}{$\begin{array}{ll}\text { MDA } & \\
\text { Max Prom }\end{array}$}} & \multicolumn{3}{|c|}{ MAA } & \multicolumn{3}{|c|}{ MDB } & \multicolumn{3}{|c|}{ MAB } \\
\hline & & & & Min & Max & Prom & Min & Max & Prom & Min & $\operatorname{Max}$ & Prom \\
\hline Azul & 0,8 & 2,8 & 1,5 & 0,8 & 2,5 & 1,5 & 1,2 & 4,3 & 2,1 & 1,0 & 6,7 & 3,0 \\
\hline Verde & 1,0 & 5,0 & 2,4 & 1,0 & 4,5 & 2,4 & 1,9 & 8,1 & 3,7 & 1,4 & 13,1 & 5,4 \\
\hline Rojo & 0,9 & 2,9 & 1,8 & 0,9 & 2,6 & 1,7 & 0,9 & 6,3 & 2,7 & 1,6 & 8,3 & 3,8 \\
\hline NIR & 16,5 & 32,8 & 26,0 & 13,3 & 30,5 & 25,0 & 2,1 & 31,0 & 20,3 & 1,6 & 32,8 & 9,8 \\
\hline \multirow[t]{2}{*}{ SWIR } & 5,4 & 14,5 & 8,5 & 5,2 & 10,0 & 7,8 & 1,4 & 15,0 & 8,3 & 1,2 & 18,0 & 5,8 \\
\hline & \multicolumn{12}{|c|}{ Landsat 8 - 2014} \\
\hline Azul & 7,9 & 14,2 & 8,3 & 7,6 & 10,6 & 8,2 & 8,1 & 11,1 & 8,6 & 8,3 & 11,2 & 9,5 \\
\hline Verde & 6,2 & 12,8 & 7,0 & 5,4 & 9,1 & 6,8 & 6,1 & 9,6 & 7,5 & 6,8 & 9,8 & 8,1 \\
\hline Rojo & 3,3 & 10,5 & 4,0 & 3,0 & 6,7 & 3,9 & 3,7 & 9,0 & 4,7 & 4,0 & 8,8 & 6,0 \\
\hline NIR & 20,1 & 34,7 & 28,9 & 12,2 & 36,5 & 27,3 & 14,1 & 33,8 & 26,6 & 9,2 & 31,1 & 19,3 \\
\hline \multirow[t]{2}{*}{ SWIR } & 7,1 & 15,7 & 9,6 & 3,8 & 11,3 & 8,9 & 5,7 & 13,0 & 10,4 & 7,0 & 16,2 & 10,4 \\
\hline & \multicolumn{12}{|c|}{ Landsat 7 - 2017} \\
\hline Azul & 0,3 & 2,7 & 1,0 & 0,0 & 2,3 & 0,7 & 1,2 & 3,2 & 0,3 & 0,5 & 4,7 & 2,2 \\
\hline Verde & 0,6 & 3,1 & 1,8 & 0,8 & 3,5 & 1,6 & 1,5 & 3,9 & 2,5 & 1,2 & 4,9 & 3,1 \\
\hline Rojo & 0,5 & 2,4 & 1,2 & 0,5 & 2,8 & 1,0 & 0,9 & 3,4 & 1,8 & 1,1 & 4,7 & 2,7 \\
\hline NIR & 28,2 & 51,2 & 43,0 & 1,8 & 48,9 & 40,8 & 16,1 & 48,9 & 40,2 & 12,0 & 47,2 & 28,7 \\
\hline SWIR & 10,0 & 19,2 & 15,2 & 8,9 & 17,2 & 14,2 & 7,2 & 20,5 & 15,9 & 4,7 & 24,4 & 12,3 \\
\hline
\end{tabular}

Donde: Mínimo (Min), Máximo (Max) y Promedio (Prom).
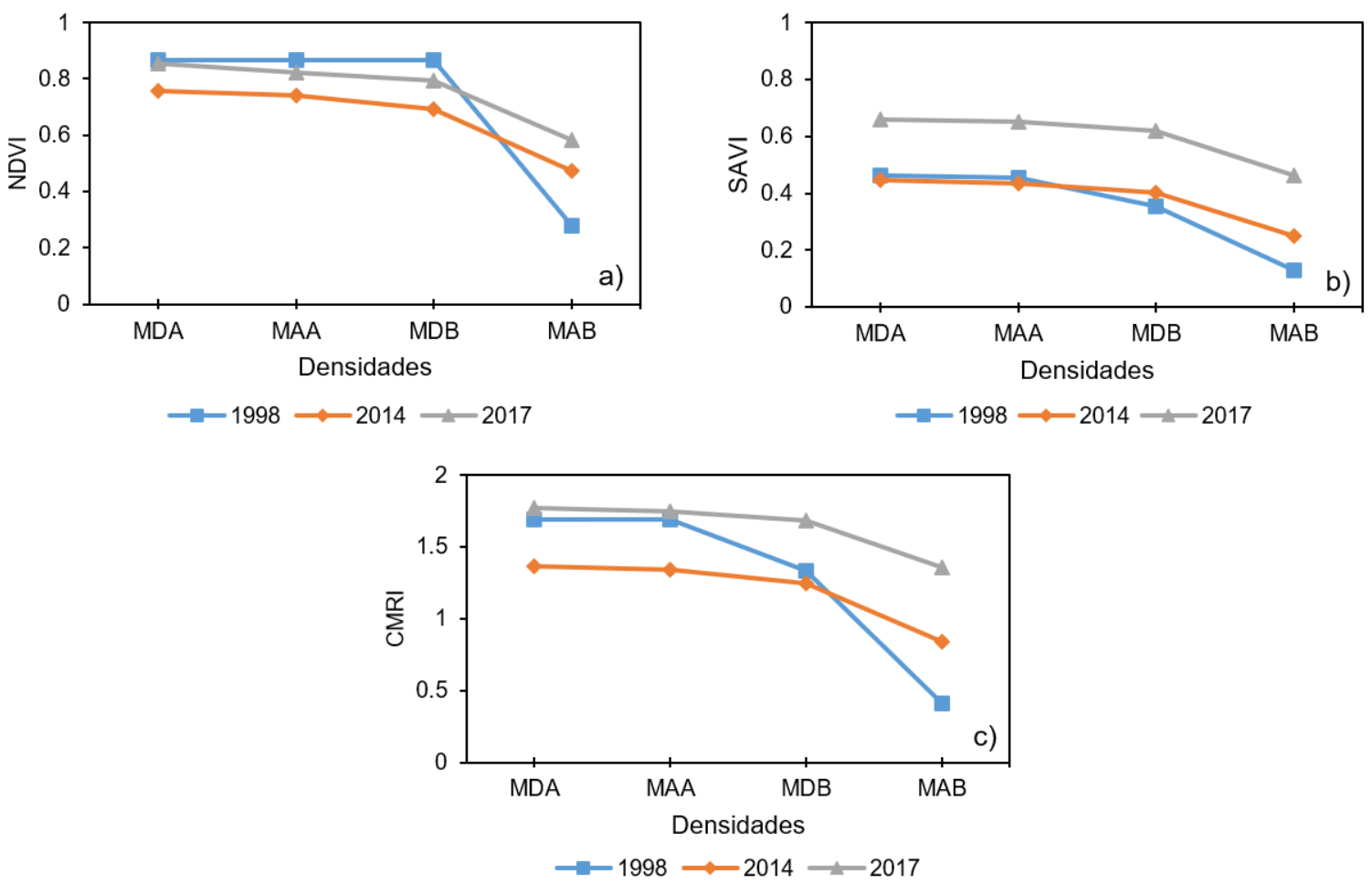

Figura 4. Valores estimados para los índices de vegetación según las densidades de bosque de manglar y temporalidad analizada a) NDVI b) SAVI y c) CMRI. Dónde: Manglar Denso Alto (MDA), Manglar Abierto Alto (MAA), Manglar Denso Bajo (MDB), Manglar Abierto Bajo (MAB). 
Tabla 8. Valores de índice de vegetación para cada densidad de bosques manglar.

\begin{tabular}{|c|c|c|c|c|c|c|c|c|c|c|c|c|}
\hline \multirow[t]{3}{*}{ Índice } & \multicolumn{12}{|c|}{ Landsat 5 - 1998} \\
\hline & \multicolumn{3}{|c|}{ MDA } & \multicolumn{3}{|c|}{ MAA } & \multicolumn{3}{|c|}{ MDB } & \multicolumn{3}{|c|}{ MAB } \\
\hline & Min & Max & Prom & Min & Max & Prom & Min & Max & Prom & Min & Max & Prom \\
\hline NDVI & $-0,6$ & 0,96 & 0,87 & $-0,2$ & 0,95 & 0,87 & $-0,6$ & 0,96 & 0,87 & $-0,62$ & 0,92 & 0,28 \\
\hline SAVI & $-0,1$ & 0,62 & 0,46 & $-0,03$ & 0,58 & 0,45 & $-0,1$ & 0,56 & 0,36 & $-0,1$ & 0,62 & 0,13 \\
\hline \multirow[t]{2}{*}{ CMRI } & $-1,3$ & 1,93 & 1,69 & $-0,5$ & 1,92 & 1,69 & $-0,9$ & 1,86 & 1,34 & $-1,34$ & 1,8 & 0,41 \\
\hline & \multicolumn{12}{|c|}{ Landsat $8-2014$} \\
\hline NDVI & $-0,1$ & 0,84 & 0,76 & 0,07 & 0,83 & 0,74 & 0,18 & 0,83 & 0,69 & 0,18 & 0,83 & 0,69 \\
\hline SAVI & 0,03 & 0,63 & 0,45 & 0,02 & 0,58 & 0,43 & 0,07 & 0,62 & 0,4 & 12 & 0,57 & 0,25 \\
\hline \multirow[t]{2}{*}{ CMRI } & $-0,4$ & 1,56 & 1,37 & $-0,1$ & 1,53 & 1,34 & 0,3 & 1,53 & 1,25 & $-0,01$ & 1,5 & 0,84 \\
\hline & \multicolumn{12}{|c|}{ Landsat $7-2017$} \\
\hline NDVI & 0,26 & 1,32 & 0,86 & 0,21 & 1,21 & 0,82 & 0,24 & 1,22 & 0,79 & 0,16 & 0,16 & 0,58 \\
\hline SAVI & 0,29 & 0,83 & 0,66 & 0,15 & 0,79 & 0,65 & 0,26 & 0,78 & 0,62 & 115 & 0,74 & 0,46 \\
\hline CMRI & 1,01 & 2,26 & 1,77 & 0,64 & 2,13 & 1,75 & 0,98 & 2,1 & 1,68 & 0,51 & 1,98 & 1,36 \\
\hline
\end{tabular}

Donde: Mínimo (Min) Máximo (Max) y Promedio (Prom).

\subsection{Monitoreo de bosques de manglar}

Se observó que entre el año 1998-2014 se registró un aumento promedio del valor del NDVI y el CMRI

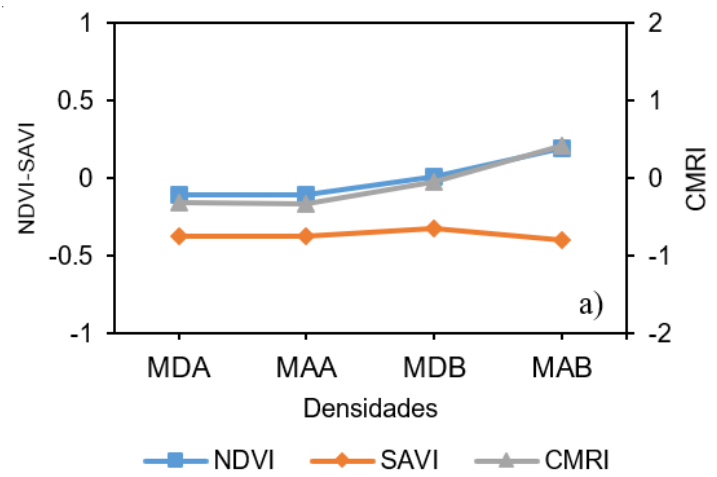

para los MAB del 0,19 y 0,42, respectivamente (Figura 5), y los aumentos se observaron sobre las zonas costeras que están en constante interacción con la marea.

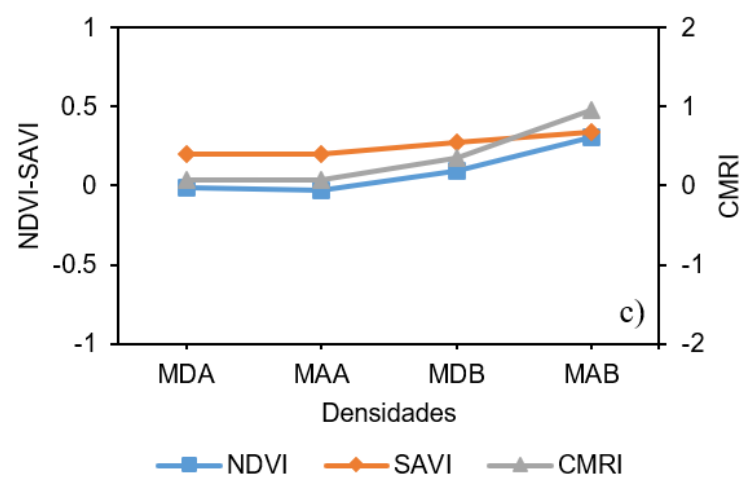

Figura 5. Comportamiento de índices de vegetación para las diferentes densidades de manglar a) 1998-2014, b)2014-2017 y c) $1998-2017$. 
Por su parte, el periodo 2014-2017 registró un aumento para los valores del SAVI superiores a 0,5 para todas las densidades. El periodo 1998-2017 registró un aumento promedio en los valores de NDVI y CMRI de 0,09 y 0,35 para los MDB y de 0,31 y 0,95 para los $\mathrm{MAB}$, respectivamente; a su vez, el SAVI presentó aumentos en el valor superiores a 0,2 en todas las densidades (Figura 6).

\section{Discusión}

La combinación de bandas espectrales es una técnica de análisis visual que permite la identificación de diferentes tipos de cobertura a través de sus características espectrales (Chuvieco, 1995; Pérez y Riva, 1998; Horning, 2014; Mohamed, 2017), y su aplicación en la BM es válida en la medida que se empleen combinaciones que resalten esta cobertura, como el infrarrojo color (NIR, Rojo, Verde) y el falso color compuesto 1 (NIR, SWIR, Rojo) concordando con lo expuesto por Pagkalinawan (2014). Sin embargo, un aspecto importante que se debe considerar al momento de realizar análisis espectrales en BM de la zona es la presencia de nubes y sombras, ya que esta región presenta un gran volumen de precipitaciones (Blanco, Escobar-Sierra y Carvajal-Quintero, 2014), las cuales pueden afectar en gran medida los valores de reflectancia del BM y pueden ser un factor limitante para llevar a cabo análisis multitemporales y de cambios primordiales para el monitoreo, tal como lo expresan Pimple y col. (2018) y (Wang y col., 2019). Si bien en este estudio se encontró una baja cobertura de nubes, el enmascaramiento eliminó una parte del manglar en la zona sur, ocasionando incertidumbre sobre los valores de reflectancia correspondientes al área eliminada.

La reflectancia de la banda infrarroja de 1998 y 2014 varió con respecto a la de 2017 entre el 12,6 y $17,9 \%$, respectivamente; sin embargo, estos valores se encuentran dentro del rango reportado por autores como Mondal, Trzaska y De Sherbinin (2018) y Perea-Ardila, Oviedo-Barrero y LealVillamil (2019). Por otra parte, el MAB para 1998 presentó un promedio de reflectancia en la banda infrarroja del $9 \%$, valor que es cercano al reportado por Vaghela y col. (2018) para manglares abiertos de la India. Los bajos valores en la reflectividad infra- rroja pueden ser provocados por el alto contenido de humedad que se presenta en los manglares por efecto del aumento de las mareas (Winarso y Purwanto, 2017; Gupta y col., 2018); por el contrario, la reflectividad en la banda infrarroja reportada para el año 2017 presentó valores altos (superiores al 40\%) para tres de las densidades de BM (MDA, MAA y MDB), mientras que el MAB obtuvo valores promedios superiores al $28 \%$ en condiciones de bajamar, resultados que coinciden con lo reportado por Zhang y col. (2017) y Xia y col. (2018).

La firma espectral de los BM puede variar debido a los efectos de la marea, por consiguiente, es afectada debido a la cantidad de agua bajo el dosel del BM al momento de la captura de las imágenes. Debido a esta situación, se pueden obtener diferentes respuestas espectrales para los BM en diferentes fechas y densidades, normalmente, se tiende a subestimar la superficie de manglares con imágenes que solo consideran un único estado mareal, siendo este último aspecto es de gran interés para la investigación de la Teledetección en manglares Zhang y Tian (2013). El comportamiento de los valores de IV de los años 2014 y 2017 fue similar al descrito para la reflectancia infrarroja, pero con una disminución sobre el valor de la imagen en pleamar; de igual forma, el valor de los IV disminuyó conforme se redujo la densidad de los BM (el NDVI y el CMRI visualizaron mejor esta situación).

La evaluación espacio-temporal de los IV (19982014, 2014-2017 y 1998-2017) se evidenció que los cambios de dichos índices ocurrieron en el periodo 1998-2014 donde se registró aumento en el valor promedio para el MAB del 19\% en el NDVI; asimismo, para el periodo 1998-2017 la variación positiva del valor promedio fue del $31 \%$ para el NDVI; sin embargo, estos variaciones en el IV se registraron sobre los BM ubicados principalmente en la franja tierra-mar, donde existe una fuerte interacción de la marea y los manglares que pudiesen estar sumergidos periódicamente, lo cual generó una diferencia entre los valores de los IV (Jia y col., 2019; Xia y col., 2020). De igual manera, cuando se realizó la comparación 2014-2017 los valores promedio del NDVI y CMRI se mantuvieron con una tendencia constante positiva cercana al valor cero (0), siendo esta la comparación de imágenes en pleamar y bajamar. 

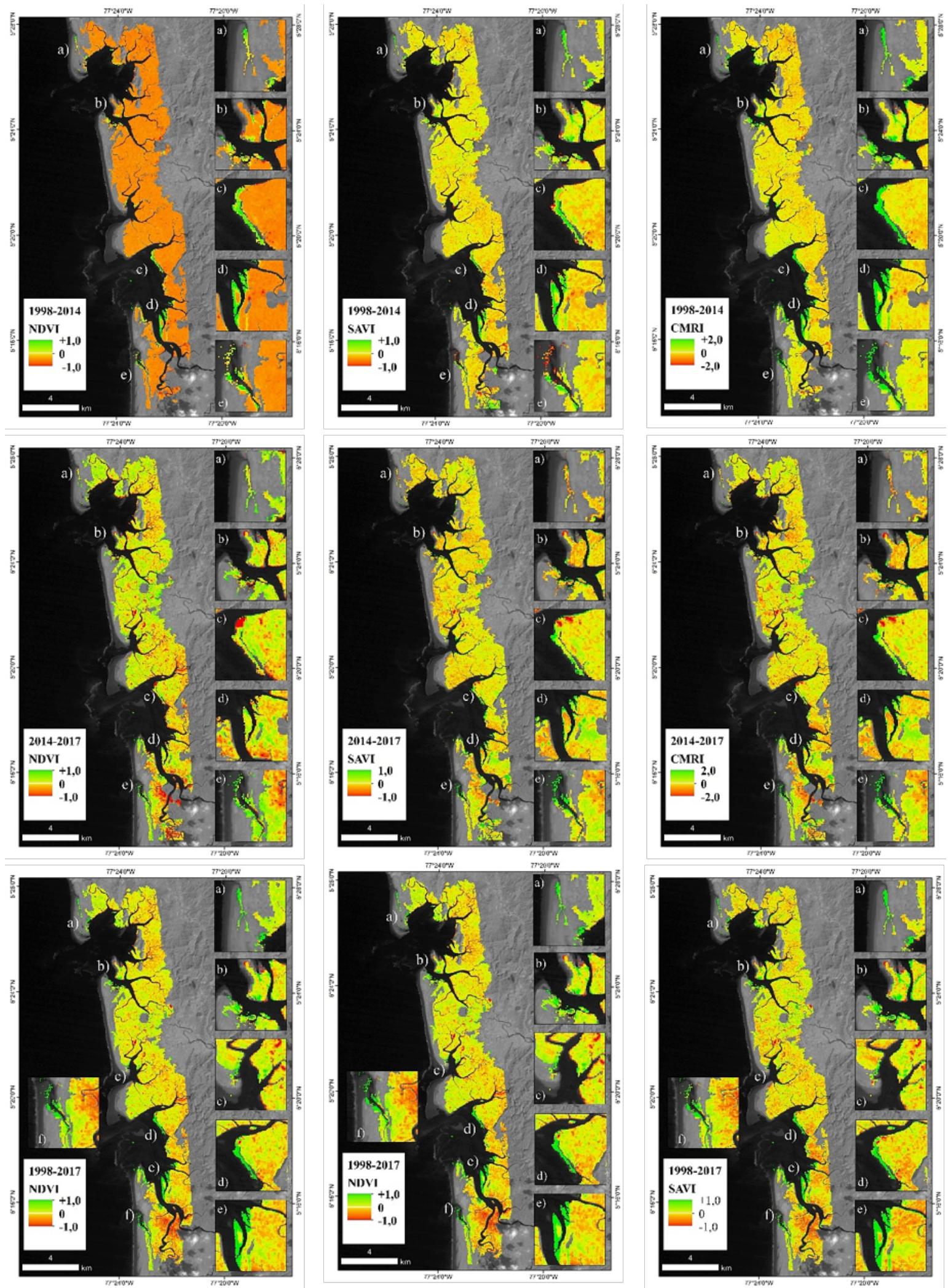

Figura 6. Índices de vegetación para el monitoreo de bosques de manglar. a), b), c), d), e), f). 
El valor de SAVI más bajo fue de $+0,13$ para los MAB de la imagen de 1998, valores que son similares a los reportados por Rhyma et al. (2020) para manglares de Malasia utilizando imágenes SPOT; sin embargo, dentro de la comparación 1998-2014 se observó que los valores promedio tuvieron tendencia hacia los cambios negativos (diminuciones que pueden superar el $30 \%$ ), mientras que para 2014-2017 los valores promedio de SAVI fueron superiores al $50 \%$ para todas las densidades. Esta variación puede estar relacionada con los hallazgos de Rhyma y col. (2020) quienes señalaron que se deben probar diferentes valores para el factor de ajuste $\mathrm{L}$ del índice SAVI en las diferentes densidades de manglar, ya que su valor debe ajustarse conforme a las condiciones de humedad del suelo por la marea en cada sitio. De igual manera, Xia y col. (2020) indicaron que el NDVI y el SAVI obtienen mejores rendimientos en manglares cuando los análisis se realizan con imágenes capturadas en marea baja, ya que el IV no pueden detectar eficientemente los manglares sumergidos, dificultando la caracterización y monitoreo.

La propuesta del CMRI es reciente, pero ha sido aplicado en diferentes estudios de monitoreo de manglares a nivel mundial (Ahmad y col., 2019; Chen, 2020; Diniz y col., 2019; Ghosh y col., 2020). Este estudio reflejó una primera aplicación del CMRI para el monitoreo de manglares en Colombia; los resultados aquí plasmados indicaron que los BM estuvieron en constante producción fotosintética a lo largo de 19 años y que el valor de los índices reflejó que los BM de ese sitio en particular se encontraban en muy buenas condiciones fisiológicas. Este IV pudiese traer mejores resultados para imágenes con diferentes condiciones de marea al eliminar el efecto de los contenidos de humedad en el suelo mediante el uso del NDWI, (Baloloy y col., 2020).

\section{Conclusiones}

Las imágenes Landsat son un recurso importante para el monitoreo de manglares, ya que permiten su identificación a través de la respuesta espectral de los BM y la posibilidad de realizar análisis espaciotemporales abarcando un largo periodo de tiempo. La identificación visual de los BM en productos Landsat debe realizarse empleando combinaciones de bandas con uso de NIR como son el infrarrojo color (NIR, Rojo, Verde) y el falso color compuesto 1 (NIR, SWIR, Rojo); en tal sentido, la respuesta espectral de los BM se ve afectada por las condiciones de humedad bajo el dosel que son ocasionadas por la fluctuación de las condiciones mareales. El uso de los IV permitió reconocer que la zona costera del área de estudio presentó constantes cambios en sus valores, principalmente influenciadas por el estado mareal. Es necesario tomar en cuenta este aspecto al momento de analizar los IV en BM, ya que es primordial para la implementación de otros procesos de análisis y clasificación más detallados, para procurar obtener la menor incertidumbre posible. Este estudio incorporó el uso del CMRI, que es un IV desarrollado específicamente para el estudio de BM y en este caso tuvo buenos rendimientos frente a los objetivos planteados. Este estudio es un referente para futuras investigaciones en la caracterización espectral y monitoreo de BM con imágenes Landsat en el litoral norte del Pacífico colombiano.

\section{Agradecimientos}

Este estudio se desarrolló bajo el contexto del proyecto denominado: "Planificación y Ordenamiento de los Litorales y Áreas Marinas Colombianas" de la Dirección General Marítima-DIMAR en Colombia, el autor principal agradece al Centro de Investigaciones Oceanográficas e Hidrográficas del Pacífico-CCCP y al laboratorio de SIG y Sensores Remotos en Tumaco por la colaboración prestada.

\section{Referencias}

Ahmad, Z. y col. (2019). «Impact of coastal development on mangrove distribution in C6YTherating Estuary, Pahang, Malaysia». En: Malaysian Journal of Fundamental and Applied Sciences 15.3, 456-461. Online:https://bit.ly/36OYYje.

Ariza, A. (2013). Descripción y Corrección de Productos Landsat 8 LDCM (Landsat Data Continuity Mission) Versión 1.0. Inf. téc. Bogotá: Centro de Investigación y Desarrollo - CIAF, Instituto Geográfico Agustín Codazzi.

Asner, G. (1998). «Biophysical and biochemical sources of variability in canopy reflectance». En: Remote sensing of Environment 64.3, 234-253. Online:https://bit.ly/3hVvgzg. 
Ávila, D. y col. (2020). «Variación espacio-temporal de la respuesta espectral en manglares de La Habana, Cuba, evaluada con sensores remotos». En: Revista de Biología Tropical 68.1, 321-335. Online:https:/ / bit.ly/3kF9SQM.

Baloloy, A. y col. (2020). «Development and application of a new mangrove vegetation index (MVI) for rapid and accurate mangrove mapping». En: ISPRS Journal of Photogrammetry and Remote Sensing 166, 95-117. Online:https: / / bit. ly $/ 2$ Tw2dcq.

Bannari, A y col. (1995). «A review of vegetation indices». En: Remote sensing reviews 13.1-2, 95-120. Online:https:/ / bit.ly/3Bw8ENw.

Blanco, J. F., C. Escobar-Sierra y J. D. CarvajalQuintero (2014). «Gorgona, Baudó y Darién (Chocó Biogeográfico, Colombia): ecorregiones modelo para los estudios ecológicos de comunidades de quebradas costeras». En: Revista de Biología Tropical 62.1, 43-64. Online:https: / / bit. ly/2UQY16z.

Chander, G. y B. Markham (2003). «Revised Landsat-5 TM radiometric calibration procedures and postcalibration dynamic ranges». En: IEEE Transactions on geoscience and remote sensing 41.11, 2674-2677. Online:https:/ / n9.cl/wygmu.

Chen, N. (2020). «Mapping mangrove in Dongzhaigang, China using Sentinel-2 imagery». En: Journal of Applied Remote Sensing 14.1, 1-11. Online:https://bit.ly/3hY0I06.

Chow, J. (2017). «Mangrove management for climate change adaptation and sustainable development in coastal zones». En: Journal of Sustainable Forestry 37.2, 139-156. Online:https:/ / bit.ly / 36UsrbI.

Chuvieco, E. (1995). Fundamentos de teledetección espacial. 2nd ed. Madrid: Ediciones RIALP S.A.

- (2010). Teledetección Ambiental. 3rd ed. Barcelona: Ariel Editorial.

Congalton, R. (1991). "A review of assessing the accuracy of classifications of remotely sensed data». En: Remote Sensing of Environment 37.1, 35-46. Online:https:/ / bit.ly/3kUfMgX.

Conti, L., C. Sampaio y M. Cunha (2016). «Spatial database modeling for mangrove forests mapping; example of two estuarine systems in Brazil». En: Modeling Earth Systems and Environment 2.73, 1-12. Online:https:/ / bit.ly/3kPkInf.

DIMAR-CCCP (2013). Zonificación fisiográfica del litoral Pacífico colombiano. Fase I. Inf. téc. Dirección General Marítima: San Andrés de Tumaco: Di- rección General Marítima-Centro de Investigaciones Oceanográficas e Hidrográficas del Pacífico.

Diniz, C. y col. (2019). «Brazilian mangrove status: Three decades of satellite data analysis». En: Remote Sensing 11.7, 1-19. Online:https: / / bit.ly / 3y78oCI.

Dirección General Marítima., ed. (2020). Red de Medición de Parámetros Oceanográficos y de Meteorología Marina (REDMPOMM). Infraestructura de Datos Espaciales Marítima, Fluvial y Costera de Colombia.

ESRI (2014). Redlands, USA.

FAO (2007). The world's mangroves 1980-2005. Food y Agriculture Organization of the United Nations.

Franco, R. (2017). Composiciones Landsat en ARCGIS. Guía Básica. MIXDYR. Online: https: / / bit.ly / 3iXYcWX.

Galeano, A. y col. (2017). "Mangrove resilience to climate extreme events in a Colombian Caribbean Island». En: Wetlands ecology and management 25.6, 743-760. Online:https : / / bit . ly / 36UD5PJ.

Gao, B. (1996). «NDWI A Normalized Difference Water Index for remote sensing of vegetation liquid water from space». En: Remote Sensing of Environment 358, 257-266. Online:https:/ / bit.ly/ $3 \times 1 \mathrm{kps} 2$.

Ghosh, S. y col. (2020). "A preliminary study on upstream migration of mangroves in response to changing environment along River Hooghly, India». En: Marine pollution bulletin 151, 1-14. Online:https://bit.ly/3iFWKYT.

Giri, C. (2016). «Observation and Monitoring of Mangrove Forests Using Remote Sensing: Opportunities and Challenges.» En: Marine pollution bulletin 8.9, 1-8. Online:https: / / bit. ly / 3iCgAV0.

Gupta, K. y col. (2018). "An index for discrimination of mangroves from non-mangroves using LANDSAT 8 OLI imagery». En: MethodsX 5, 1129-1139. Online:https:/ / bit.ly /2UzJIEz.

Holdridge, L. (1978). Ecología basada en zonas de vida. Centro Interamericano de Documentación e Información Agrícola-IICA.

Horning, N. (2014). Selecting the appropriate band combination for an RGB image using Landsat imagery Version 1.0. American Museum of Natural History, Center for Biodiversity y Conservation. 
Huete, A. (1988). «A soil-adjusted vegetation index (SAVI)». En: Remote sensing of environment 25.3, 295-309. Online:https://bit.ly/3zuX8jY.

Jia, M. y col. (2019). «New Vegetation Index to Detect Periodically Submerged Mangrove Forest Using Single-Tide Sentinel-2 Imagery». En: Remote Sensing 11, 1-17.Online: https : / / bit.ly / 3iToERo.

Kuenzer, C. y col. (2011). «Remote sensing of mangrove ecosystems: A review». En: Remote Sensing 3.5, 878-928. Online:https:/ / bit.ly/2UHovII.

Mohamed, E. (2017). «Consideration of landsat-8 Spectral band combination in typical mediterranean forest classification in Halkidiki, Greece». En: Open Geosciences 9.1, 468-479. Online:https: / / bit.ly/36Zo7Yt.

Mondal, P., S. Trzaska y A. De Sherbinin (2018). «Landsat-derived estimates of mangrove extents in the Sierra Leone coastal landscape complex during 1990-2016». En: Sensors 18.12, 1-15. Online:https://bit.ly/3BxOpiF.

Monirul, I., B. Helena y K. Lalit (2018). «Monitoring mangrove forest land cover changes in the coastline of Bangladesh from 1976 to 2015». En: Geocarto International 31.13, 1458-1476. Online:https:/ /bit.ly/2VbEcI1.

Muhsoni, F. y col. (2018). "Comparison of different vegetation indices for assessing mangrove density using sentinel-2 imagery». En: Int. J. Geomate 14, 42-51. Online:https:/ / bit.ly/3eMwOcT.

Omar, H., M. Misman y V. Linggok (2018). «Characterizing and monitoring of mangroves in Malaysia using Landsat-based spatial-spectral variability». En: IOP Conference Series: Earth and Environmental Science. Vol. 169, 24-25. Online:https: //bit.ly/3hWSAwK.

Pagkalinawan, E. (2014). «Mangrove forest mapping using Landsat 8 images». En: State of the mangrove summit: Northwestern Luzon Proceedings, 60-64. Online:https:/ / bit.ly/2TxBOLj.

Perea-Ardila, M., F. Oviedo-Barrero y J. LealVillamil (2019). «Cartografía de bosques de manglar mediante imágenes de sensores remotos: estudio de caso: Buenaventura, Colombia.» En: Revista de Teledetección 53.1, 73-86. Online:https: / / bit.ly/3ygOWU8.

Pérez, F. y J. De la Riva (1998). «El empleo de imágenes Landsat TM para la detección y cartografía de áreas incendiadas en el Prepirineo occidental oscense». En: Geographicalia 36, 131-145. Online:https://bit.ly/36XtEij.
Pham, T. y col. (2019). «Remote sensing approaches for monitoring mangrove species, structure, and biomass: Opportunities and challenges». En: Remote Sensing 11.3, 1-24. Online:https: / / bit.ly / 3rFlMf2.

Pimple, U. y col. (2018). «Google earth engine based three decadal landsat imagery analysis for mapping of mangrove forests and its surroundings in the trat province of Thailand». En: Journal of Computer and Communications 6, 246-264. Online:https:/ / bit.ly/3BBa7SU.

Purwanto, A. y W. Asriningrum (2019). «Identification of mangrove forests using multispectral satellite imageries». En: International Journal of Remote Sensing and Earth Sciences (IJReSES) 16.1, 63-86. Online:https://bit.ly/36YbtJn.

Rebelo-Mochel, F. y F.J. Ponzoni (2007). «Spectral characterization of mangrove leaves in the Brazilian Amazonian Coast: Turiaçu Bay, Maranhão State». En: Anais da Academia Brasileira de Ciências 79.4, 683-692. Online:https:/ / bit.ly/3rEKZGj.

Rhyma, P. y col. (2020). «Integration of normalised different vegetation index and Soil-Adjusted Vegetation Index for mangrove vegetation delineation». En: Remote Sensing Applications: Society and Environment 17, 1-70. Online:https: / / bit.ly / 3y2s4ru.

Rodríguez-Rodríguez, J.A. y col. (2016). «The Wetland Book». En: Dordrecht: Springer Netherlands. Cap. Mangroves of Colombia.

Rouse, J., J. Haas R. Shell y D. Deering (1974). Monitoring vegetation systems in the Great Plains with ERTS. Goddard Space Flight Center.

USGS (1998). «USGS EROS Archive - Landsat Archives - Landsat 4-5 Thematic Mapper (TM) Level-1 Data Products». En: Landsat 4-5 TM Collection 1. Landsat Scene ID LT50100561998003CPE00. U.S Geological Survey. Online:https://bit.ly/3b7KDjI.

- (2014). «USGS EROS Archive - Landsat Archives - Landsat 8 OLI Level-1 Data Products». En: Landsat 8 Operational Land Imager (OLI) Collection 1. Landsat Scene ID LC80100562014239LGN01. U.S Geological Survey. Online:https: / / bit.ly / 3b7KDjI.

- (2017). «USGS EROS Archive - Landsat Archives - Landsat 7 ETM+ Level-1 Data Products». En: Landsat 7 Enhanced Thematic Mapper Plus (ETM+) Collection 1. Landsat Scene ID LE70100562017111EDC00. U.S Geological Survey. Online:https://bit.ly/3b7KDjI. 
- (2018a). Landsat 7 Data Users Handbook. Version 2.0. Inf. téc. U.S Geological Survey.

- (2018b). Landsat 8 Data Users Handbook - Versión 3.0. Inf. téc. U.S Geological Survey.

- (2020). EarthExplorer. Prog. U.S Geological Survey.

Umroh, A. y S. Sari (2016). «Detection of mangrove distribution in Pongok Island». En: Procedia Environmental Sciences 33, 253-257. Online:https: $/ / \mathrm{n} 9 . \mathrm{cl} / \mathrm{w} 48 \mathrm{~d}$.

Vaghela, B. y col. (2018). «Multi criteria decision making (MCDM) approach for mangrove health assessment using geo-informatics technology». En: International Journal of Environment and Geoinformatics 5.2, 114-131. Online:https: / / bit.ly / 3rx4Zuo.

Wang, L. y col. (2019). "A review of remote sensing for mangrove forests: 1956-2018». En: Remote Sensing of Environment 231, 1-150. Online:https: //bit.ly/2WcAxdr.

Wilkie, M. y S. Fortuna (2003). Status and trends in mangrove area extent worldwide. Food y Agriculture Organization of the United Nations.

Winarso, G. y A. Purwanto (2017). «Evaluation of mangrove damage level based on Landsat 8 image». En: International Journal of Remote
Sensing and Earth Sciences 11.2, 105-116. Online:https:/ / bit.ly/3rutwjS.

Xia, Q. y col. (2018). «Mapping mangrove forests based on multi-tidal high-resolution satellite imagery». En: Remote Sensing 10.1343, 2-20. Online:https:/ / bit.ly/316iPD5.

Xia, Q. y col. (2020). «Evaluation of submerged mangrove recognition index using multi-tidal remote sensing data». En: Ecological Indicators 113, 1-140. Online:https://bit.ly/3kRKpDH.

Zhang, X. y Q. Tian (2013). «A mangrove recognition index for remote sensing of mangrove forest from space.» En: Current Science 105.8, 1149-1155. Online:https://bit.ly/3i0V11a.

Zhang, X. y col. (2017). "Mapping mangrove forests using multi-tidal remotely-sensed data and a decision-tree-based procedure». En: International journal of applied earth observation and geoinformation 62, 201-214. Online:https: / / bit.ly / 3i0jVOr.

Zhu, Z. y C. Woodcock (2014). «Automated cloud, cloud shadow, and snow detection in multitemporal Landsat data: An algorithm designed specifically for monitoring land cover change». En: Remote Sensing of Environment 152, 217-234. Online:https://bit.ly/3ByuHDD. 